\title{
An operative dengue risk stratification system in Argentina based on geospatial technology
}

\author{
Ximena Porcasi ${ }^{1}$, Camilo H. Rotela ${ }^{1}$, María V. Introini ${ }^{2}$, Nicolás Frutos ${ }^{2}$, Sofía Lanfri ${ }^{1}$, \\ Gonzalo Peralta $^{1}$, Estefanía A. De Elia ${ }^{1}$, Mario A. Lanfri ${ }^{1}$, Carlos M. Scavuzzo ${ }^{1}$ \\ ${ }^{1}$ Comisión Nacional de Actividades Espaciales, Falda del Carmen, Ruta E45, Km 8, Córdoba, Argentina; \\ ${ }^{2}$ Dirección de Enfermedades Transmisibles por Vectores, Ministerio de Salud de La Nación, 9 de Julio 341, \\ Córdoba, Argentina
}

\begin{abstract}
Based on an agreement between the Ministry of Health and the National Space Activities Commission in Argentina, an integrated informatics platform for dengue risk using geospatial technology for the surveillance and prediction of risk areas for dengue fever has been designed. The task was focused on developing stratification based on environmental (historical and current), viral, social and entomological situation for >3,000 cities as part of a system. The platform, developed with open-source software with pattern design, following the European Space Agency standards for space informatics, delivers two products: a national risk map consisting of point vectors for each city/town/locality and an approximate $50 \mathrm{~m}$ resolution urban risk map modelling the risk inside selected high-risk cities. The operative system, architecture and tools used in the development are described, including a detailed list of end users' requirements. Additionally, an algorithm based on bibliography and landscape epidemiology concepts is presented and discussed. The system, in operation since September 2011, is capable of continuously improving the algorithms producing improved risk stratifications without a complete set of inputs. The platform was specifically developed for surveillance of dengue fever as this disease has reemerged in Argentina but the aim is to widen the scope to include also other relevant vector-borne diseases such as chagas, malaria and leishmaniasis as well as other countries belonging to south region of Latin America.
\end{abstract}

Keywords: dengue, decision informatics support, geomatics, risk, Argentina.

\section{Introduction}

Dengue, including dengue fever, dengue hemorrhagic fever and dengue shock syndrome, is a leading emerging tropical disease, considered of high importance not only in terms of morbidity and mortality but also due to its economic impact (Martinez Torres, 2008). The disease infects between 50 and 100 million individuals each year and is responsible for over 500,000 hospital admissions per year. An average of 22,000 people dies annually because of the disease, thus three times exceeding the mortality of influenza AH1N1 in 2009. The causative agent is a mosquito-borne flavivirus (family: Flaviviridae), transmitted to humans by the bite of Aedes aegypti, the main vector in South America. There are four different virus serotypes (DEN $1,2,3,4)$, and infection with any of them results in flulike symptoms providing specific protection against that serotype but only partial immunity against the

\section{Corresponding author:}

Ximena Porcasi

Comisión Nacional de Actividades Espaciales, Falda del Carmen

Ruta E45, Km 8, Córdoba, Argentina

Tel. +54 3547431 000; Fax +543547431046

E-mail:ximena.porcasi@conae.gov.ar others. A second infection with another serotype triggers the more serious hemorrhagic form of the disease (Estrada-Franco and Craing, 1995).

Multiple environmental factors, including biophysical and social ones, constitute a complex web that determines the spread of vector-borne diseases (Tauil, 2001; Hales et al., 2002). While demographic, anthropogenic and bioclimatic factors act specifically on the insect populations, the weather conditions influence their spatio-temporal distribution (Micieli and Campos, 2003). During the first half of the $20^{\text {th }}$ century, Ae. aegypti was distributed both in northern and central Argentinean provinces but the mosquito was eliminated in 1963 (Bejarano, 1968; Carcavallo and Martínez, 1968) due to a successful campaign carried out by the Ministry of Health $(\mathrm{MoH})$ in Argentina in collaboration with the Pan American Health Organization (PAHO), forerunner of the World Health Organization (WHO). However, it was reintroduced in Brazil in 1975 (Schatzmayr, 2000) and later also in Argentina. The re-infestation of Ae. aegypti was discovered in 1986 in the Misiones and Formosa provinces (Carbajo et al., 2001), expanding southward (Santa Rosa, La Pampa province) (Rossi et al., 2006) and westward 
(Guaymallén, Mendoza province) (Domínguez et al., 2000). In the first half of 2009 , an epidemic of dengue of serotype 1 occurred in the Salta and Jujuy provinces, then spreading to the East and South reaching the $35^{\circ}$ parallel. It resulted in 25,989 confirmed cases in total in the country (Ministerio de Salud de la Nación, 2010), but only 1,706 new dengue cases were reported in the following year (Ministerio de Salud de la Nación, 2011) indicating that this dengue outbreak was over. On the other hand, the increased challenge for the health authorities at this time coincided with strong development and increased accessibility of geospatial technology offering the opportunity to link remote sensing and the need for health information.

In the last 10 years, progress have been made on the epidemiology of dengue and other diseases depending on vector-borne diseases such as malaria, leishmaniasis and Argentinean hemorrhagic fever thanks to the interdisciplinary landscape epidemiology concept, which aims to produce predictive risk models based on landscape elements in addition to field data (Tran et al., 2004; Porcasi et al., 2005, 2006; Salomón et al., 2006; Arboleda et al., 2009). This pioneering work was developed by applying space technology to epidemiological problems carried out in USA and Europe (Beck et al., 2000; Hay, 2000; Ostfeld et al., 2005). Due to the success of landscape epidemiology, it seemed adequate to implement these ideas into operative projects, useful to health authorities and researchers alike. This challenge has moved the development of the health application project (HAP) forward and we present an early warning system (EWS) based on geospatial technology in an interdisciplinary and inter-institutional context. The platform was developed using Open Source Software (OSS) (Tokar et al., 2011; Ullah and Khan, 2011) in order to obtain a low-cost product with respect to pattern design and object-oriented concepts (Booch, 1998; Shuang and Peng, 2009). The European Space Agency standards for space informatics projects (ESA, 2011) were followed at all stages of the development.

The present work describes the design and implementation of the dengue risk stratification system (DRS) at the national and the urban levels, aiming at supporting the strategic surveillance activities of the $\mathrm{MoH}$.

\section{Materials and methods}

As a consequence of the stated user requirements (Box 1), the system was designed to generate two final products and a suite of intermediate subproducts as follows:

(i) Risk stratification at the national level: a vector layer (shapefile format based on latitudes, longitudes and datum WGS84) where each locality/city is represented by a point and variables associated through a .dbf file. This stratification is performed by algorithms, which are fed with four blocks of information including environmental remotely sensed data from the Moderate Resolution Imaging Spectroradiometer (MODIS) (http://modis.gsfc.nasa.gov/), viral, entomological and vector control data.

(ii) Risk stratification at the urban level: a raster layer (geotiff format) with $15 \mathrm{~m}$ pixel size based on macro-environmental information from Advanced Spaceborne Thermal Emission and Reflection Radiometer (ASTER) and/or Satellite Pour l'Observation de la Terre (SPOT) in addition to other factors such as urban facilities and population distribution plus entomological surveys and case data (whenever available).

\section{Architecture of the informatics platform}

Requirements specification, system design description and interface definition were undertaken during the development of the system. The software was developed under the standards of the European Space Agency (ESA, 2011). Since the operability would be facilitated if it is configurable and can be maintainable over time, the architecture of our HAP system is modular, versatile and flexible consisting of five subsystems as shown in Figure 1.

The data translation (DT) subsystem receives data uploaded by users in spreadsheet format, e.g. Exel, and is responsible for validation and conversion of data into extensible markup language (XML) format, which remain available for future queries. It consists of three units:

(i) the Uploader Web Interface unit provides the graphical user interface in order to upload the spreadsheet to the server and it is also responsible for the management of user messages;

(ii) the $\mathrm{Xls} 2 \mathrm{xml}$ unit is in charge of format conversion, creating and storing files from standard xls format of excel spreadsheets into XML format; and

(iii) the Translators units, whose main function is to verify and store the data uploaded by the user.

The algorithm executor (AE) subsystem is in charge of managing the execution of algorithms and it consists of: 
(i) The Algorithm Execution Manager unit, which executes each algorithm according to a set of predefined control rules (in XML format) in order to generate each product posted on the HAP server. It saves its output in the SD subsystem.

(ii) The xmlParser unit, which prepares the input data for each algorithm from XML files generated from data entered by users. For each algorithm, there is a Process_ $i$ unit executing it. Hence, to update a given product, or to add a new one, means only to update or to add one unit to the system. Each unit is robust, in the sense that the corresponding algorithm can be executed even in the case the input data set is not complete. The mathematical models are written in algorithms that can be developed by different researchers and even be programmed in different languages. In order to provide uniform interfaces to the system (in terms of inputs and outputs) we adopted the "wrapper" concept, in which each algorithm is encapsulated in a unit.
The spatial data (SD) subsystem is in charge of storing and managing the output data of the DT and AE subsystems. It stores data in XML and GeoTIFF format.

The visualization (VZ) subsystem presents the results to the user via the Internet (web-based). It has functions that allow querying, navigation, exploration and printing the products (e.g. maps) posted on the server via the GeoServer. It provides various base layers, e.g. from Google, OpenLayersGoogle or Bing.

The alarm trigger (AT) subsystem should be executed when an emergency event occurs. This subsystem is so far only defined, not yet implemented. It consists of two units:

(i) the Emergency Manager unit, which allows modification of the rules of the Algorithm Execution Manager unit, for example the algorithm execution frequency; and

(ii) the Emergency Interface unit that presents a graphical interface to the authorized user in order to trigger the emergency event.

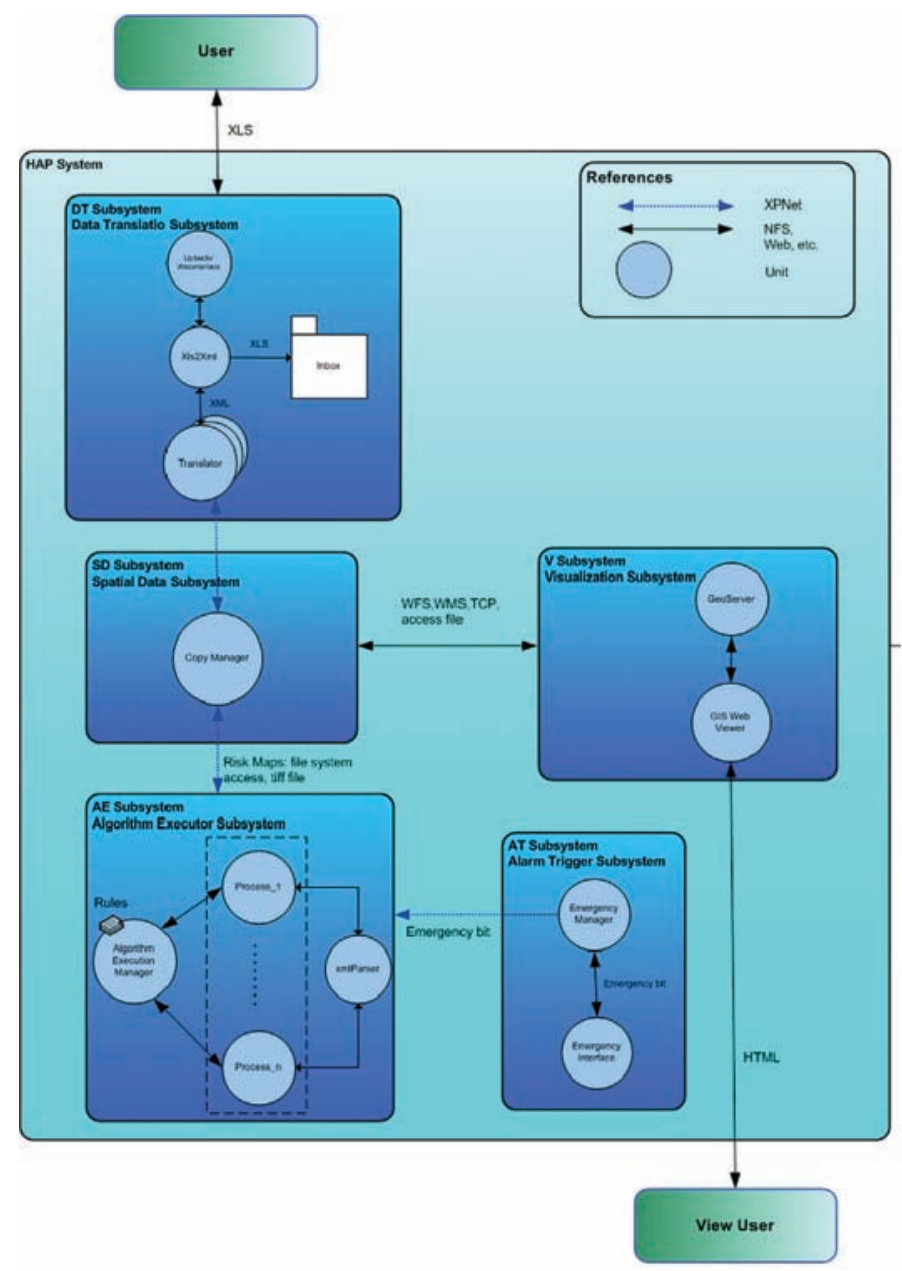

Fig. 1. The HAP architecture with its five subsystems and inter-phases. The blue boxes represent the subsystems, arrows the type of inter-phase used and circles the operational units within each subsystem. 


\section{Design concepts and implemented technologies}

The system presented here was conceived using both design patterns concepts and object-oriented programming (based on open-source tools). Application of design patterns provides an efficient way to create a more flexible, elegant and reusable object-oriented software, being a pre-requirement to define suitable objects, to create its classes and to define the inheritance hierarchies and the interfaces, while taking into account its interrelations (Booch, 1998; Ullah and Khan, 2011).

As mentioned above, we used the GeoServer map server, which is an open-source server (in Java format) that allows users both to view and edit geospatial data. Users can access visible data layers through this geographic data management unit. GeoServer uses standards set forth by the Open Geospatial Consortium (OGC; http://www.opengeospatial.org/) allowing a great flexibility in map creation and data sharing. Due to the implementation of Web Feature Service (WFS), Web Coverage Service (WCS) and Web Map Service (WMS) protocols, GeoServer can create maps in a variety of output formats (such as TIFF or vector layers).

GeoExplorer, an open-source web application for composing and publishing maps, was adopted in order to get a proper visualization of the spatial data. It assembles maps from GeoServer and integrates with hosted maps such as Google Maps and/or OpenStreetMap. It edits map styling information graphically, embeds composed maps in any web page and outputs them in PDF format. GeoExplorer is based on the GeoExt JavaScript libraries and is built using GXP components (http://gxp.opengeo.org/master/doc/). Communications between GeoServer and GeoExplorer are obtained via the WMS and WFS protocols.

To upload the spreadsheet, a graphical interface was implemented using the Google Web Toolkit (GWT) that allowed us to create and compile AJAX applications in JavaScript. GWT is a set of opensource development tools used for building and optimizing complex browser-based applications. As seen above in the system architecture section, the SD subsystem validates saves and sends the spreadsheet by e-mail. These functions were implemented by a Web Service, for which the Web Services Description Language (WSDL) forms the basis. Briefly, a Web Service Consumer performs validation of input data and then sends the form using the service-oriented architecture protocol (SOAP) (a set of principles for designing and developing software in the form of interoperable services) to the Web Service Provider, which performs all the validation logic of the data from the national epidemiological spreadsheet based on the Spring Web Services (http://static.springsource.org/spring-ws/sites/2.0/). A WSD contract, defining the message format, data types, transport protocols, etc. and containing the semantics and exchange mechanism between provider and consumer, is finally established between the consumer and the provider to ensure correct data validation.

\section{User input risk components}

As stated above, in addition to the environmental component, there are three other components, based on information that health agents/users at the provincial level, which should be uploaded (via an Excel file) to the system. If no data are uploaded by a given locality, a flag is added to the map annotating "No uploaded data" for that location. Each of the components summarises different aspects suggested for dengue risk evaluation (OPS, 1995):

(i) "Ac Control" is the block characterizing the locality regarding to mosquito populations control actions that are developed periodically. It evaluates both (a) periodicity and (b) personal affected by the control activities;

(ii) "Vi Viral" circulation is the component related with the present and historical autochthonous circulation of virus in the given locality. It evaluates (a) method of syndrome surveillance, (b) autochthonous transmission, (c) population fluxes, (d) population density and (f) border proximity; and

(iii) "Ve Entomological" considers the present presence of the vector at the given locality. It evaluates (a) certified presence of Ae. aegypti, (b) entomological indexes (LIRAa) and (c) the percentage of houses with water supply.

These components were evaluated by local health agents, scored for risk from 1 (lowest) to 4 (highest) and combined with the environmental risk (described in next section) according to eq. 1 in order to obtain the final dengue virus risk where a higher figure represents a higher risk.

\section{Algorithms and process running at Algorithm Executor in the HAP system}

\section{Risk algorithm at the national level description}

The total risk of dengue virus circulation is calculated at each locality, in base of four complementary 
components, as follows:

$$
T_{\text {RISK }}=V_{e}^{*}\left(V_{i}+V_{a m b}+A_{c}\right)
$$

where $V_{e}$ is the entomological component, $V_{i}$ the viral one, $V_{a m b}$ the environmental one and $A_{c}$ the component related to the control activities undertaken. Whilst each one of these component has values from 1 to 4 , the final result is classified by a four colored point vector layer as low, medium, high and very high risk, respectively.

\section{Environmental component $\left(V_{\text {amb }}\right)$}

The environmental risk is the geometric average of two parts: (i) the bio-geographical macro-conditions determining the presence of the vector (considered stationary or not time dependent); and (ii) a component involving both, the dynamical development of vector's population and the viral cycle length, which are basically temperature-dependant.

$$
\left.V_{\text {amb }}=\operatorname{sqrt}\left(V_{\text {ectorpresence }} * V_{\text {iralcycle }}\right) \quad \text { (eq. } 2\right)
$$

The vector-presence probability sub-component

We applied ecological modelling ideas in order to calculate the probability of presence of the dengue vector using historical environmental variables and vector species presence localization data. We used 451 Argentine sites of Ae. aegypti presence from the literature (Vezzani and Carbajo, 2009) and updated it with data from the $\mathrm{MoH}$ related to the 2009 dengue outbreak. In addition, we used 461 sites pseudo-absences. The environmental historical data set consists of 18 variables in raster format having a $1 \mathrm{~km}$ pixel size (see auxiliary list for data access). For the generation of vector presence probability maps we used two different approaches and their geometric means as a final operative result. The first methodology was the Maximum Entropy method based on the MaxEnt 3.3.3a software (Phillips et al., 2006), reserving 25\% of the presence points for validation and carried out 10 repetitions. The second methodology was to perform logistic regression (Martínez-Freiría et al., 2008), using SPSS17.0 based on the Wald forward stepwise method with a cut on 0.6 and 20 iterations, in which we included all the significant variables $(\mathrm{P}<0.05)$. As shown in Fig. 2, similar results were obtained applying both methodologies showing the higher probability of presence in rainforest regions progressively decreasing southward until latitude $41^{\circ}$ South. Areas where the mosquito presence is zero have a null risk of dengue virus circulation. Measurement accuracy, the area under the curve (AUC) in receiver operating characteristic (ROC) analysis, scored 0.81 for MaxEnt and 0.73 for the logistic regression maps.
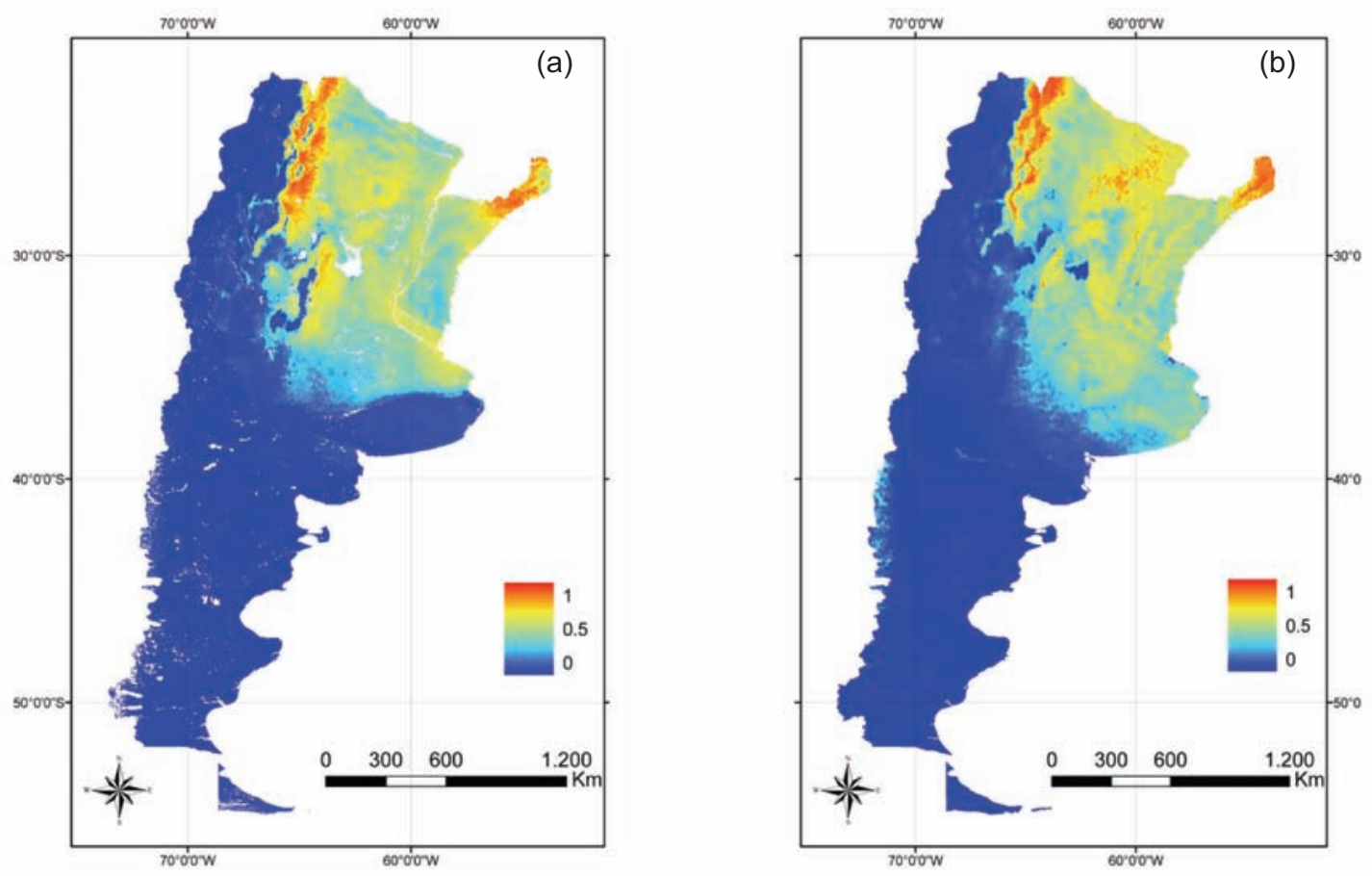

Fig. 2. Probability of Ae. aegypti presence obtained by MaxEnt (a) and logistic regression (b). Values close to one (red) indicate the most suitable habitats for mosquito presence. 


\section{Vector and virus cycle component risk}

Following Focks et al. (1993a, b), we estimated this risk component as proportional to the number of viral extrinsic incubation periods (EIP) completed in each locality. EIP and mosquito lifespan are basically functions of the daily mean temperature. It is similar to the approach applied by Carbajo et al. (2001), but we updated the EIP dynamically as a function of temperature within the framework of an operative system. Due to both the spatial coverage (more than 3,000 Argentinean localities) and the required temporal resolution, we used the land surface temperature (LST) data from MODIS onboard the Terra and Aqua satellites, which made it possible to estimate the LST with an error about 1 centigrade. This approach has been used with reasonable good results in epidemiological studies (Tatem et al., 2004). The Ae. aegypti life cycle is driven by environmental factors, mainly the temperature. For example, a range of $0{ }^{\circ} \mathrm{C}$ to $40^{\circ} \mathrm{C}$ has been reported as adequate for mosquito survival (Carbajo et al., 2001). Based on that, our simplified model starts in the cold season and takes into account one year of data, simulating a new mosquito life cycle when the temperature (according to MODIS) is greater than $16^{\circ} \mathrm{C}$ (assuming the minimum temperature for that day could be $5{ }^{\circ} \mathrm{C}$ lower) and when the mosquitoes reach the mature stage, EIP duration is calculated. The sequence of the mosquito dynamic simulation can be summed up as follows:

(i) temperature evaluation $\left(>16^{\circ} \mathrm{C}\right.$ is required to start the simulation);

(ii) day-degree calculation (suitable days are cumulated in terms of day-degrees for the mosquito to become adult);

(iii) calculation of completed EIPs (using Focks et al. (1993a, b), the percentage of completed EIPs is calculated daily and, assuming a mean mosquito life time of 20 days, that percentage is added to previous days to evaluate if the corresponding EIP was completed); and

(iv) counting the number of completed EIPs however the cycle is reset (starts again at step a) each time the temperature falls below $5{ }^{\circ} \mathrm{C}$ to ensure that only completed cycles are counted.

Following this rule along one-year time series, the number of viral cycles is calculated at each pixel. For example, the application of the above algorithm to localities in northern Argentina (subtropical) in a typical year yields about 16 completed cycles; meanwhile in the centre of our country (temperate) only about 11 cycles are completed. After normalization, this raster layer is added to the vector presence component to generate the "environmental risk stratification" vector layer for each locality of Argentina. This product could be updated monthly but in an operative regime it is calculated twice a year. The result for 2010 is presented in Fig. 3, where it can be seen that almost all the localities in the country are able to develop at least one EIP cycle. The environmental risk stratification resulting from eq. 2 is shown in Fig. 4.

\section{Risk stratification at the urban level}

The objective of this product is to produce dengue risk cartography at the urban level, following the landscape epidemiology ideas that have been explored previously (Rotela et al., 2007, 2010, 2011; Estallo et al., 2008). The basic risk concept was formulated as:

$$
\text { Risk }=\text { Threat } \mathrm{x} \text { Vulnerability }
$$

The inputs in this model are: (i) high-resolution (if available) or medium-resolution remotely sensed images with urban cartography (streets, parks, distances to bus stations, cemeteries and schools); (ii) LST; (iii) socio-economic conditions according to the latest national census (INDEC, 2001); (iv) percent of domiciliary water (Water\%) and waste collection service (Waste\%); and (v) population density and signs of overcrowding. Also vector field data as larval indexes (by LIRAa for example), vector control actions and location of cases are included as inputs. Fig. 5 show the conceptual sketch of the implemented model. In it, the Threat is modelled by two factors, viral circulation $\left(V_{C}\right)$ (if available) and putative Ae. aegypti habitats $\left(P_{b}\right)$ (Rotela et al., 2007). $P_{b}$ attempts to predict urban areas with more probability of vector presence are calculated as follows:

\section{Putative habitat estimation}

If mosquito field data are available, a linear regression is performed using the equation

$$
P_{b}=F(\text { Land use, LST, Water } \%, \text { Waste } \% \text {, Cemetery })
$$

to adjust the available field data. If not, a conceptual additive model as follows

$$
\begin{gathered}
\left.P_{b}=F(\mathrm{LST})+\text { land use - mean (Water } \%, \text { Waste } \%\right) \\
\text { - cemetery distance }
\end{gathered}
$$




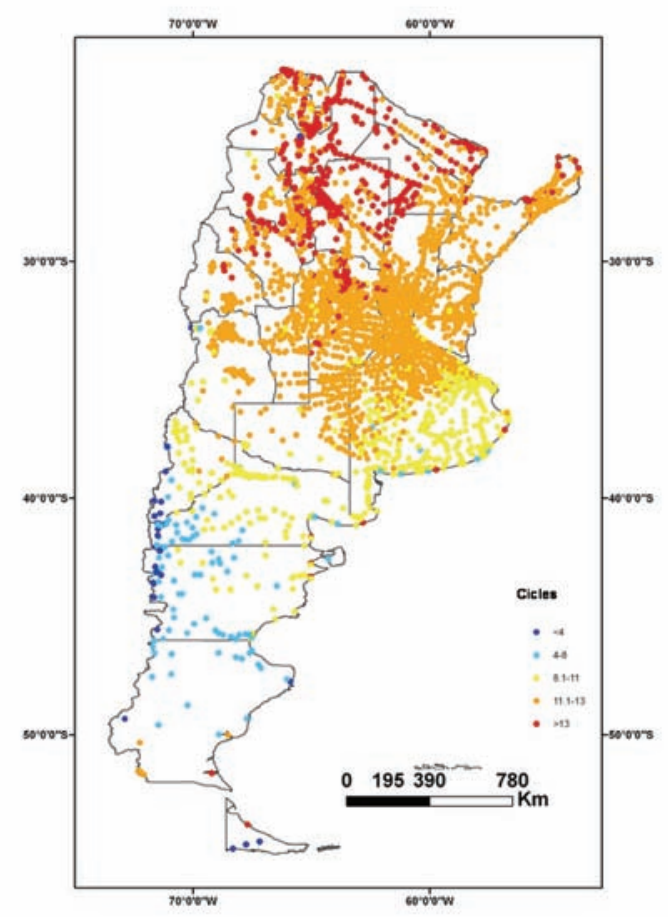

Fig. 3. The virus incubation component: numbers of EIP completed in one year (as function of daily temperature data, LST) using the algorithm explained in the text for each locality.

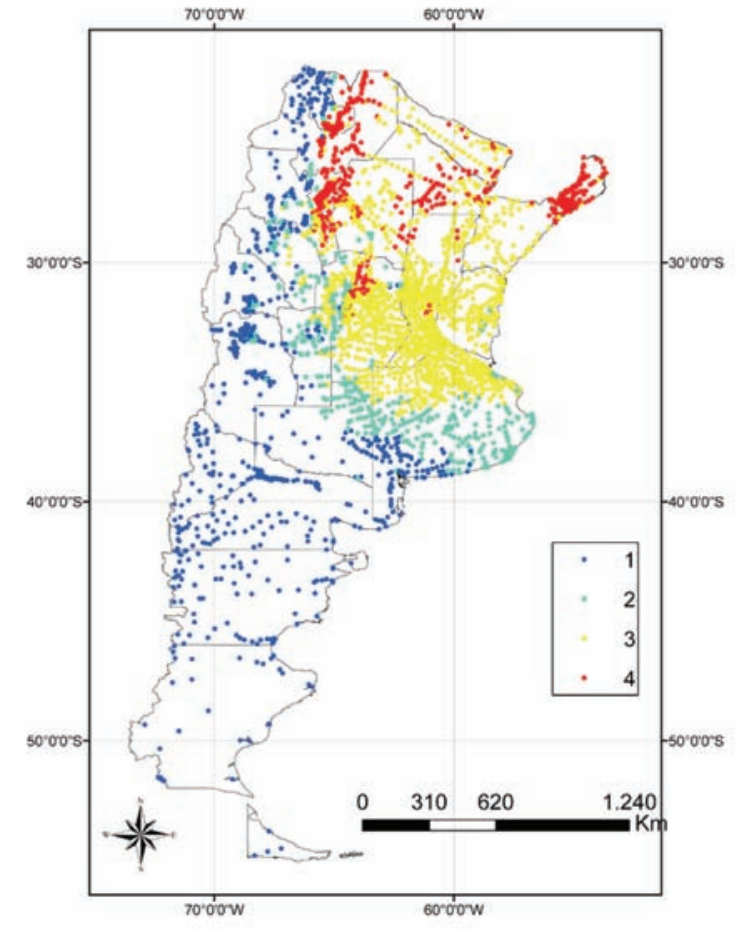

Fig. 4. Environmental risk stratification combining vector presence probability and dynamic virus incubation components. The risk is standardized and classified in four risk categories (increasing from blue to red).

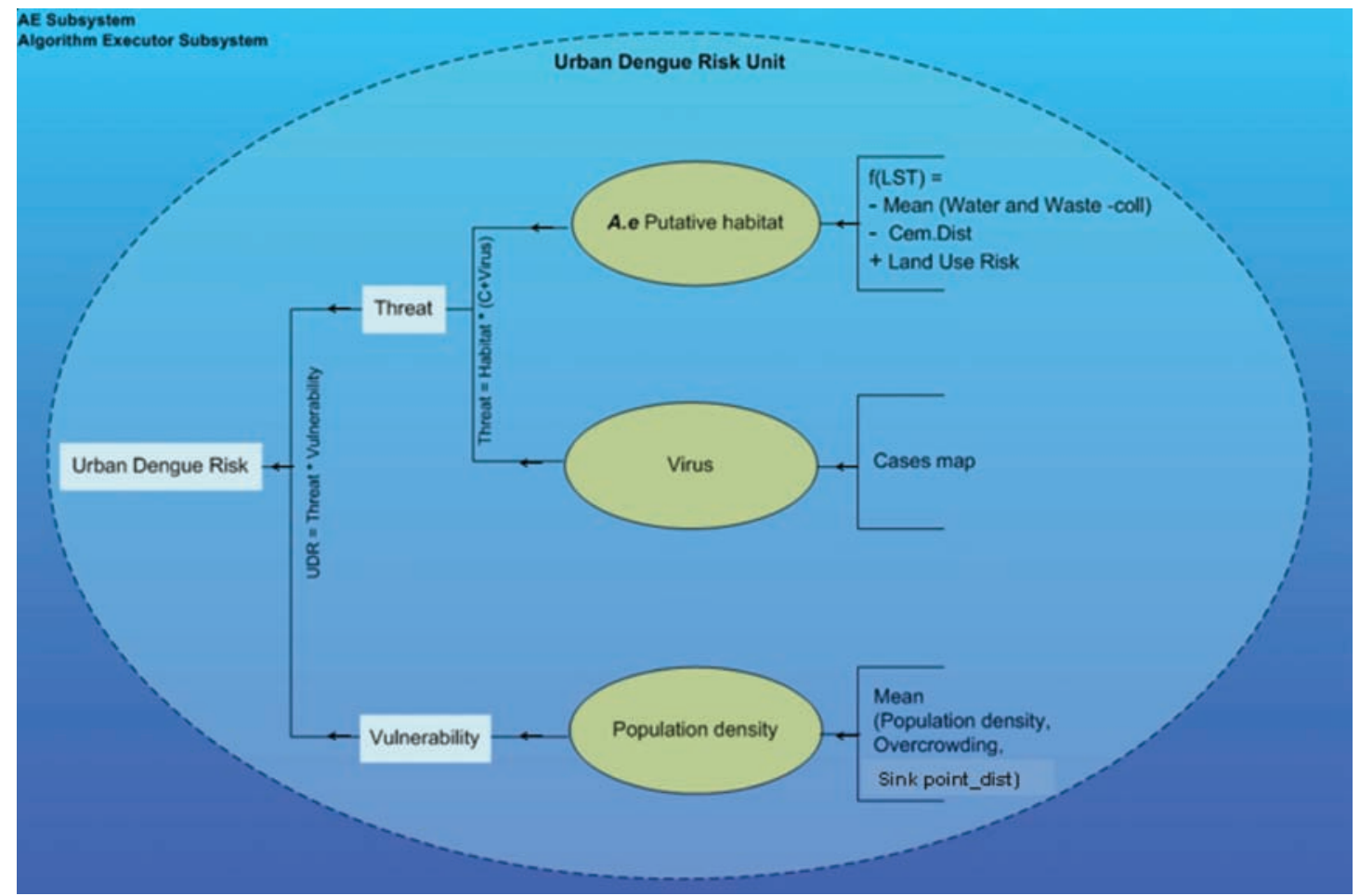

Fig. 5. Design of the urban dengue risk unit. The three sub-products of the urban algorithm (Ae. aegypti putative habitat, virus circulation and exposed population or vulnerability) are represented by yellow ovals with the sub-product inputs indicated at right. Arrows indicate the processing sequence. 


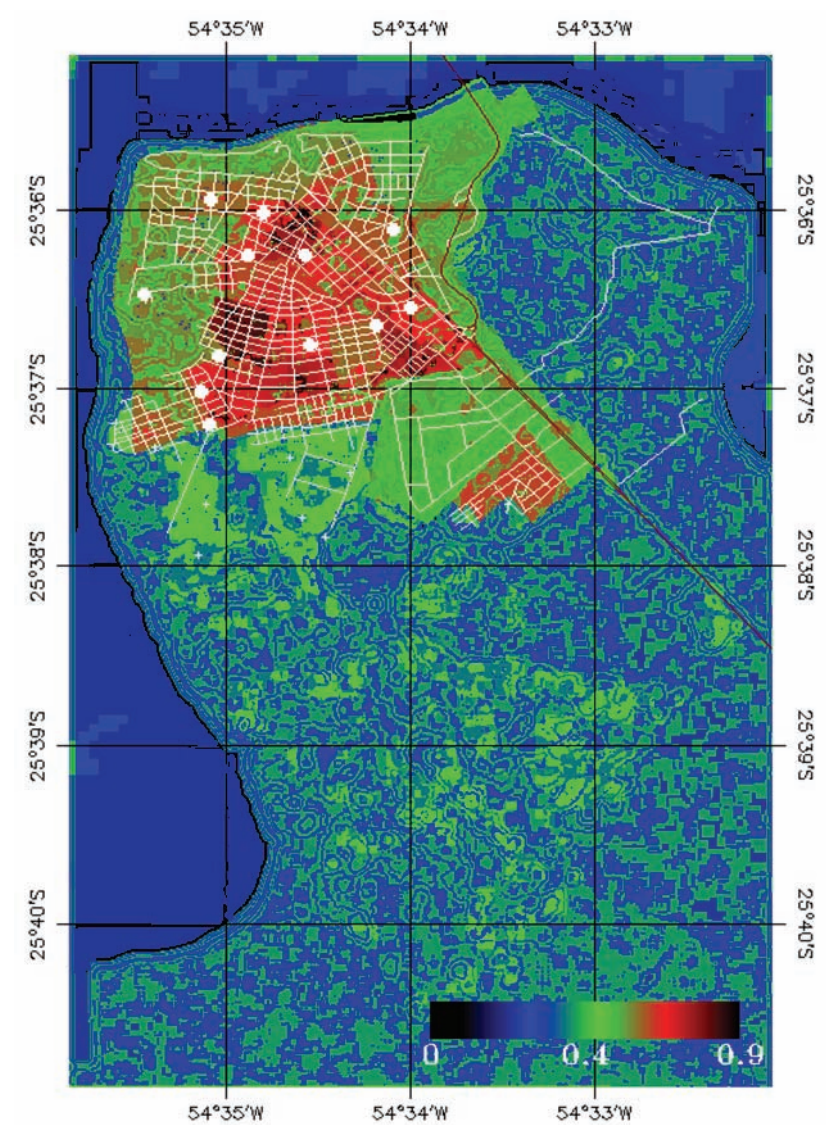

Fig. 6. Urban risk for Iguazú city and its peri-urban area. Risk ranges from 0 to 1 as indicated by the colour ramp. White dots represent the centroids of neighborhoods with confirmed cases during 2009.

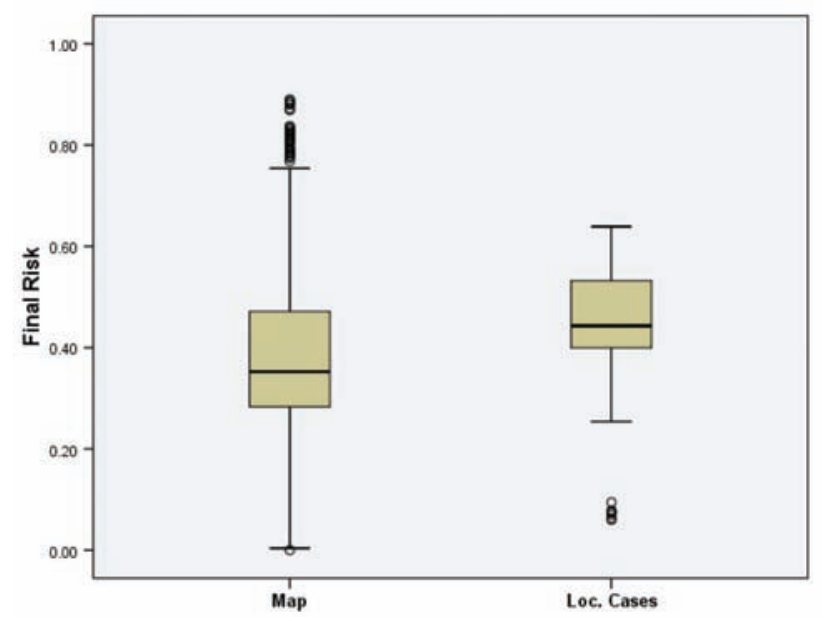

Fig. 7. Box plot comparing statistics of two urban risk map areas: (a) the map of all Iguazú and (b) centroids areas of neighbourhoods with positive cases in 2009 (the white dots in Fig. 8). Risk mean difference between both areas is 0.068 (Wilcoxon test $=1.731 \mathrm{E} 9, \mathrm{P}<0.001)$. where variables have been previously normalized to range from 0 to 1 . In case of vector data being limited to only a small part of the city, both methodologies are applied. Remotely sensed data were used to generate a land cover classification with the following informational classes: Bare soil, low vegetation (grass), high vegetation (trees), urban buildings, and other (the last one includes crops). Using a $200 \mathrm{~m}^{2}$ kernel and this land cover classification, we obtained two raster products of particular interest: the most frequent and the second most frequent cover class (in a $100 \mathrm{~m}$ radius neighbourhood that represents the Ag. aegypti active flying distance (discussed in Otero et al., 2008 to be between 100 and $200 \mathrm{~m}$ ) surrounding each pixel. In order to find an initial approach to risk due to land cover, a decision tree based on a previous paper on environmental characterization of the Ae. aegypti positive breeding sites (Rotela et al., 2010) was applied Besides potential habitat, a density map based on positives human cases will be included for the "Threat" sub-product estimation. Spatial analysis of these cases is also planned as a possible sub-product of urban risk maps.

\section{Vulnerability}

Vulnerability $(V)$ is modelled as the mean of a set of standardized variables obtained from the national census (e.g. overcrowding and population density) and from cartography by the following equation:

$$
V=\text { mean }\left(D_{B S}, D_{S}, O_{V}, P_{D}\right)
$$

where $D_{B S}$ and $D_{S}$ are the distance to bus stations and to schools, respectively, $O_{V}$ the overcrowding index and $P_{D}$ the population density. The Puerto Iguazú dengue risk, presented in Fig. 6 was calculated considering "Threat" equal to Ae. aegypti putative habitat, because of the lack of individual geo-referenced cases. The resulting final risk map is spatially heterogeneous, and the overlay of located cases is shown in Fig. 7. This heterogeneity is generated by the optical and thermal input data. Because Iguazú is a growing city, some areas in the south-east have not been censed yet (revealed as linear edges and colour changes). The peri-urban area is changing and there exists a progressive cover replacement from rain forest to crops or inhabited areas showing low risk. On the other hand, the downtown area has a higher risk due to edification, surface temperature and population density. This methodology is in process to be automated but is still manual. 
At present, 48 localities have been uploaded for the set of input data to create the national-scale risk level for dengue (Fig. 8a). Figure $8 \mathrm{~b}$ presents the system working at the urban scale showing a risk map overlayed onto Google Earth. For the urban level the risk has continuous values, whereas at the national level it has four discrete values. Red colour represents high risk at both levels.

\section{Discussion}

The modular design of the DRS informatics platform allows operational flexibility and enables the visualization of intermediate products of the risk assessment process evaluating different aspects of vector control and surveillance activities in detail. The general architecture makes the platform applicable for risk mapping of many different vector-borne diseases. In addition, it does not require professional specialization and provides thus a userfriendly tool for all endusers and decion makers.

A similar client-server design has been proposed for a schistosomiasis EWS in China (Yang et al., 2012). Delayed response and expensive software were mentioned by Yang et al. (2012) as obstacles for a fully GIS-based EWS application in epidemiology. Reliance on open-source technologies is therefore important as it guarantees that time and cost is reasonable. In our particular case, initial system requirements (Box 1) were supported by the $\mathrm{MoH}$ and the design, implementation and maintanance of the platform was developed in collaboration with the National Space Activities Commission in Argentina (CONAE) (http://www.conae.gov.ar/principal.html). This design envisages a continuous upgrade of the biologic algorithms on specific processing units. Figs. $8 \mathrm{a}$ and $8 \mathrm{~b}$

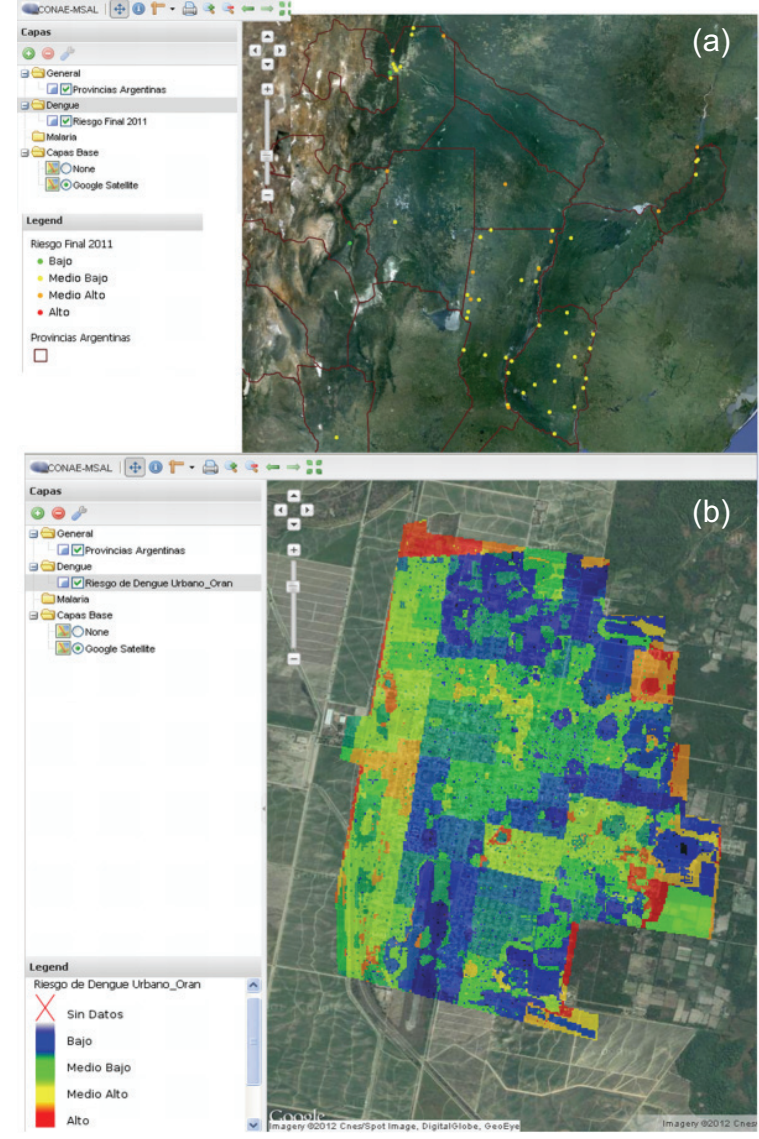

Fig. 8. Screen shots of running systems: (a) the national level product showing the final dengue risk in the 48 localities including different risk components, which can be visualized as different GIS layers (see selectable layers at left of the image); (b) The Orán city shows the urban risk level indicated by colour scale (red $=$ highest risk) and different available GIS functionalities (measure distances, zooms, etc.)

show screenshots of the running system, where operational functionalities such as zoom, distance measurement, layers selections and overlays (including Google Earth layers) can be seen. Internet and spatial visuali-

Box 1. User requirements and products.

This operative system is based on user requirements that were stated after several meetings between health decision makers at both the national and provincial levels. It was agreed that the system should:

(i) be able to support both multiple diseases and multiple scales of risk;

(ii) estimate the risk stratification by applying a multifactor approach at the national level for all the localities;

(iii) also produce risk cartography at the urban level;

(iv) facilitate decision making;

(v) update environmental conditions based on remotely sensed data;

(vi) integrate information such as viral circulation, urbanization, entomological field data and population parameters;

(vii) be expandable in order to cover others regional countries without significant change;

(viii) make information and maps accessible via the Internet (SIG Web based user interface);

(ix) be developed at low cost (open-source preferable);

(x) be free of charge for all end users;

(xi) be operative (running) steadily by an expected life time of $>5$ years;

(xii) be user friendly in order to interact with non-informatic specalist staff in the provinces; and

(xiii) aim at eventually involve the whole country. 
Box 2. Auxiliary data for vector presence probability component.

- Precipitation: first and second components from Principal Components Analysis (PCA 1 and PCA 2) over a time series of monthly precipitation from 1950 to 2000 (Hijmans et al., 2005)

- Normalized difference vegetation index (NDVI) and land surface temperature (LST): PCA 1 and PCA 2 over a 1982 to 2000 time series from the Advanced Very High Resolution Radiometer (AVHRR-NOAA) explained in detail in (Porcasi et al., 2005)

- SRTM Dem: altitude from the Shuttle Radar Topography Mission (SRTM) mission from NASA (http://www2.jpl.nasa.gov/srtm/)

- Annual mean temperature (Bio1), temperature seasonality (Bio4), annual precipitation in $\mathrm{mm}$ (Bio12) and precipitation seasonality (Bio15) from Worldclim (http://www.worldclim.org/current)

- Water soil content stress and water soil balance for both PCA 1 and PCA 2 and the annual soil water balance (http://www.cgiarcsi.org/data/climate)

- Annual potential evapotranspiration (http://www.cgiar-csi.org/data/item/51-global-aridity-and-pet-database)

- Soil classes (http://www.ambiente.gov.ar/aplicacion=mapoteca\&idseccion=76\&IdApli=2. INTA)

- Land cover (http://www.diva-gis.org/data/DataServer.htm)

zation technologies are being considered widely as a powerful tool for epidemiological surveillance.

The modelling incorporated in the system, both for the national and urban levels, reflects epidemiological considerations of field data and daily experiences with the aim of including those inputs and risk factors that are truly available at the operational level. As discussed by Kitron et al. (2006), fine-scale resolution data can provide detailed information on the processes driving disease clustering allowing control programmes to target disease sources more efficiently. However, decision making at the $\mathrm{MoH}$ often takes place on a coarser resolution, both at the spatial and the temporal levels. That duality justifies the use of national as well as urban analysis. Besides, the system combines landscape epidemiology concepts and research on vector-borne diseases, in this case dengue, supported by research experience in Latin America and new evidence (Porcasi et al., 2005, 2006; Salomón et al., 2006; Rotela et al., 2007, 2010). At the urban level, different risk factors were studied and the relations between mosquito presence and human cases seem to vary from place to place. Specifically in South America, approaches including social and environmental variables including remote sensing (Flauzino et al., 2009; Marcelhas and Rodrigues, 2011) allowing the possibility of presenting a model based on suggestions by experts and data availability. The results of the specific models implemented at both levels, agree reasonably well with the sets of field data available, but more accurate tests are planned with the inclusion of current data of entomological indices and human cases.

The system is robust in the sense that it can produce risk stratification even if the complete set of input data is not available. CONAE provides remote sensing data, e.g. land cover and LST, which are updated at different frequencies according to the algorithm used, those data ensures a minimal risk map output. In order to improve accuracy, the system has the possibility of continuous algorithm upgrading. Besides that, spatial analysis of both vector presence and human cases are already under development in order to determine spatio-temporal changes in dengue incidence as proposed by Khormi et al. (2011).

Together with the DRS system implementation, training activities were conducted in different regions of the country. These activities combined DRS specific use with a revision of epidemiological standard indexes and actions suggested by the $\mathrm{MoH}$ going along with health policies oriented to standardize measures for dengue risk in the country. Because of the open-access architecture and easy visualization, the tool brings a direct feedback of the epidemiologic data from (or to) the localities of interest. As users are responsible for part of the input data, this feedback encourages data collection and sharing of basic field information with the health system. It also allows evaluation of endusers with regard to operation of the system; local authorities can evaluate local risk as well as that of the immediate surrounding areas, including the national risk.

At the present time, 48 localities are sharing this system and the number should increase during this year. It is also being used by the $\mathrm{MoH}$, where it was positively received and suggested to be expanded to include countries in the region (Mercosur). Although several aspects of the system could (and will) be improved, we believe strongly in its operational usefulness based on the interesting work that landscape epidemiology has offered.

\section{Acknowledgements}

We thank Dr. Francisco Garcia, Dr. Alberto Gentile and Dr. Mirtha Eiman from Salta Province Epidemiology Direction and 
Dr. Carlos Ripoll from Jujuy Province Epidemiology Direction for their valuable discussion on risk factors inputs. This work was supported by the Comisión Nacional de Actividades Espaciales (CONAE) and National Health Ministery. CONAE also provided technological support for geo-server placement and high resolution images for urban risk maps.

\section{References}

Arboleda S, Jaramillo N, Peterson AT, 2009. Mapping environmental dimensions of dengue fever transmission risk in the Aburrá Valley, Colombia. Int J Envron Res Public Health 6, 3040-3055.

Beck LR, Lobitz BM, Wood BL, 2000. Remote sensing and human health: new sensors and new opportunities. Emerg Infect Dis 6, 217-227.

Bejarano JF, 1968. History of urban and wild yellow fever in the Republic of Argentina. Rev Sanid Mil Arg 67, 211-256.

Booch G, 1998. Object-oriented analysis and design with applications. Santa Clara. Addison-Wesley Press, 2nd ed.

Carbajo AE, Schweigmann N, Curto SI, De Garín A, Bejarán R, 2001. Dengue transmission risk maps of Argentina. Trop Med Int Health 6, 170-183.

Carcavallo RU, Martínez A, 1968. Fiebre amarilla, vectores y cadena epidemiológica. Comunicaciones científicas - entomoepidemiología de la República Argentina, investigaciones científicas de las Fuerzas Armadas Argentinas 1, 105-144.

Domínguez MC, Ludueña Almeida F, Almirón W, 2000. Dinámica poblacional de Aedes aegypti (Diptera: Culicidae) en Córdoba capital. Rev Soc Ent Argentina 59, 41-50.

Estallo EL, Lamfri MA, Scavuzzo CM, Almeida FFL, Introini MV, Zaidenberg M, Almirón WR, 2008. Models for predicting Aedes aegypti larval indices based on satellite images and climatic variables. J Am Mosq Control Assoc 24, 368-376.

ESA, 2011. Bssc guides and reports, Ed by European Space Agency, 2011. http://www.esa.int/TEC/Software_engineering_and_standardisation/TECT5CUXBQE_0.html (accessed on July 2012)

Estrada-Franco J, Craig G, 1995. Biología, relaciones con enfermedades y control de Aedes albopictus. Cuaderno Técnico 42. Eds OPS, Washington.

Flauzino R, Souza-Santos R, Oliveira R, 2009. Dengue, geoprocessamento e indicadores socioeconomicos e ambientais: um estudo de revisao. Rev Panam Salud Publ 25, 456-461.

Focks DA, Haile DG, Daniels E, Mount GA, 1993a. Dynamic life table model for Aedes aegypti (Diptera: Culcidae). Analysis of the literature and model development. J Med Entomol 30, 1003-1017.

Focks DA, Haile DG, Daniels E, Mount GA, 1993b. Dynamic life table model for Aedes aegypti (Diptera: Culicidae): simulation and validation. J Med Entomol 30, 1018-1028.

Hales S, De Wet N, Maindonald J, Woodward A, 2002.
Potential effect of population and climate changes on global distribution of dengue fever. An empirical model. Lancet 360, 830-834.

Hay SI, 2000. An overview of remote sensing and geodesy for epidemiology and public health application. Adv Parasitol 47, 1-35.

Hijmans RJ, Cameron SE, Parra JL, Jones PG, Jarvis A, 2005. Very high resolution interpolated climate surfaces for global land areas. Int J Climatol 25, 1965-1978.

INDEC, Censo nacional de población y viviendas, 2001. Instituto nacional de estadísticas y censos, Ministerio de Economía, Buenos Aires, Argentina.

Khormi HM, Kumar L, Elzahrany RA, 2011. Modeling spatiotemporal risk changes in the incidence of dengue fever in Saudi Arabia: a geographical information system case study. Geospat Health 6, 77-84.

Kitron U, Clennon JA, Cecere MC, Gürtler RE, King CH, Vazquez-Prokopec G, 2006. Upscale or downscale, applications of fine scale remotely sensed data to Chagas disease in Argentina and schistosomiasis in Kenya. Geospat Health 1, 49-58.

Marcelhas I, Rodrigues MA, 2011. Uso de imagens de alta resoluçao espacial para análise da diferenciaçao socioespacial em sao josé dos campos. In Anais XV simpósio brasileiro de sensoriamento remoto - remoto (SBSR), 30 Apr - 5 May 2011, Curitiba, PR, Brazil. Edited by Neves Epiphanio and Galvao, 838-846.

Martínez-Freiría F, Sillero N, Lizana M, Brito JC, 2008. GISbased niche models identify environmental correlates sustaining a contact zone between three species of european vipers. Divers Distrib 14, 452-461.

Martinez Torres E, 2008. Dengue. Estud. av. vol. 22 São Paulo. Available from: http://www.scielo.br/scielo.php?script=sci_arttext\&pid=S0103-40142008000300004\&lng. ISSN 0103-4014.

Micieli MV, Campos RE, 2003. Oviposition activity and seasonal pattern of a population of Aedes (Stegomyia) aegypti (L.) (Diptera: Culicidae) in subtropical Argentina. Mem Inst Oswaldo Cruz 98, 659-663.

Ministerio de Salud de la Nación, 2010. Situación de dengue en Argentina. Parte de prensa $\mathrm{N}^{\circ} 23$. http://www.msal.gov.ar/ dengue/partes/Parte23.pdf (accessed on November 2011)

Ministerio de Salud de la Nación, 2011. Informe de vigilancia de dengue. Área de vigilancia. Dirección de epidemiología. Dirección de enfermedades transmitidas por vectores. Actualización al 21/01/2011.

OPS, 1995. Dengue y dengue hemorrágico en las Américas. Guías para su prevención y control. Publicación Científica $\mathrm{N}^{\circ}$ 548. Washington.

Ostfeld RS, Glass GE, Keesing F, 2005. Spatial epidemiology. An emerging (or re-emerging) discipline. Trends Ecol Evol 20, 328-336.

Otero M, Schweigmann N, Solari HG, 2008. A stochastic spa- 
tial dynamical model for Aedes aegypti. Bull Math Biol 70, 1297-1325.

Phillips S, Anderson R, Schapire R, 2006. Maximum entropy modeling of species geographic distributions. Ecol Model, 190, 231-259.

Porcasi X, Calderón G, Lamfri L, Polop J, Sabattini M, Scavuzzo CM, 2005. Predictive distribution maps of zoonoses reservoir rodents in a southern America. Masto Neotrop 12, 199-216.

Porcasi X, Catalá SS, Hrellac H, Scavuzzo MC, Gorla DE, 2006. Infestation of rural houses by Triatoma infestans (Hemiptera: Reduviidae) in southern area of Gran Chaco in Argentina. J Med Entomol 43, 1060-1067.

Rossi GC, Lestani EA, D’Oria JM, 2006. Nuevos registros y distribución de mosquitos de la Argentina (Diptera: Culicidae). Rev Soc Entomol Argent 65, 51-56.

Rotela CH, Fouque F, Lamfri M, Sabatier P, Introini V, Zaidenberg M, Scavuzzo CM, 2007. Space-time analysis of the dengue spreading dynamics in the 2004. Tartagal outbreak, Northern Argentina. Acta Trop 103, 1-13.

Rotela CH, Espinosa MO, Albornoz C, Lafaye M, Lacaux JP, Tourre YM, Vignolles MC, Scavuzzo CM, 2010. Desarrollo de mapas predictivos de densidad focal de Aedes aegypti en la ciudad de Puerto Iguazú (Argentina), basados en información ambiental derivada de imágenes Spot 5 HRG1. Revista SELPER 30, ISSN 0717-2915.

Rotela CH, Spinsanti LI, Lamfri MA, Contigiani MS, Almirón WR, Scavuzzo CM, 2011. Mapping environmental susceptibility to Saint Louis encephalitis virus, based on a decision tree model of remotely sensed data. Geospat Health 6, 85-94.

Salomón OD, Orellano PW, Lamfri MA, Scavuzzo CM, Dri, L,
Farace MI, Quintana DO, 2002. Phlebotominae spatial distribution asssociated with a focus of tegumentary leishmaniasis in Las Lomitas, Formosa, Argentina. Mem Inst Oswaldo Cruz 101, 295-299.

Schatzmayr HG, 2000. Dengue situation in Brazil by year. Mem Inst Oswaldo Cruz 95, 179-181.

Shuang L, Peng C, 2009. Developing java EE applications based on utilizing design patterns. WASE International Conference on Information Engineering, ICIE, 2 art. 5211375, 398-401.

Tatem AJ, Goetz SJ, Hay SI, 2004. Terra and Aqua: new data for epidemiology and public health. Int J Appl Earth Obs 6, 33-46.

Tauil PL, 2001. Urbanization and dengue ecology. Cad Saude Publica 17, 99-102.

Torkar R, Minoves P, Garrigós J, 2011. Adopting free/libre/open source software practices, techniques and methods for industrial use. J Assoc Inf Syst 12, 88-122.

Tran A, Deparis X, Dussart P, Morvan J, Rabarison P, Remy F, Polidori L, Gardon J, 2004. Dengue spatial and temporal patterns, French Guiana. Emerg Infect Dis 10, 615-621.

Ullah K, Khan SA, 2011. A review of issue analysis in open source software development. J Theor App Inf Tech, 23, 98108.

Vezzani D, Carbajo AE, 2008. Aedes aegypti, Aedes albopictus, and dengue in Argentina: current knowledge and future directions. Mem Inst Oswaldo Cruz 103, 66-74.

Yang K, Sun LP, Huang YX, Yang GJ, Wu F, Hang DR, Li W, Zhang JF, Liang YS, Zhou XN, 2012. A real-time platform for monitoring schistosomiasis transmission supported by Google Earth and a web-based geographical information system. Geospat Health 6, 195-203. 